\title{
Los estilos de El rey Lear. \\ Consideraciones de una traductora
}

María Enriqueta GONZÁLEZ PADILlA

Universidad Nacional Autónoma de México

"En ninguna parte - dice Ifor Evans- fueron las intenciones de Shakespeare por lo que respecta a la lengua más complejas, ni su éxito más completo que en El rey Lear". ${ }^{1}$ En efecto, esta obra, quizá la más trascendental del autor, sobresale en toda su producción por la habilidad con que la poesía está al servicio del designio dramático. "Poesía" implica, en este caso, el manejo de una variedad asombrosa de recursos, de una gama muy variada de estilos, los cuales deben quedar reproducidos en una traducción que aspire a ser poética y se precie de ser fiel. Quiero dar algunos ejemplos sobre lo que ha sido mi experiencia en este sentido, por lo que toca a la traducción de El rey Lear para la colección Nuestros clásicos, de la UNAM.

Comenzaré por citar aquel pasaje del acto III, escena ii, en que Lear, frenético en medio de la tempestad, desfoga en la naturaleza su indignación por la ingratitud de sus hijas. Nótese cómo el apóstrofe a los elementos desencadenados presta a este parlamento una memorable dimensión épica:

LEAR: Blow, winds, and crack your cheeks! rage! blow!

You cataracts and hurricanes, spout

Till you have drench'd our steeples, drown'd the cocks!

You sulph'rous and thought-executing fires,

Vaunt-couriers of oak-cleaving thunderbolts,

Singe my white head! And thou, all-shaking thunder,

Strike flat the thick rotundity o'th'world!

Crack Nature's moulds, all germens spill at once

That makes ingrateful man!

( $i$ Bufad, vientos, y haced que estallen vuestras mejillas!

¡Enfurecéos! ¡Bufad! Vosotros cataratas y huracanes,

'Ifor Evans, The Language of Shakespeare's Plays. Londres, Methuen, 1964, p. 171. 
diluviad hasta que hayáis inundado nuestros campanarios y sumergido sus veletas. ¡Vosotros, fuegos sulfúricos que transcurrís raudos como pensamientos y sois precursores de las centellas que hienden los robles, achicharrad mi cabeza blanca! ¡Y tú, trueno, que todo haces temblar, de un golpe arrasa la gruesa redondez del mundo, rompe los moldes de la Naturaleza, y haz que de una vez se derramen todos los gérmenes que producen al hombre ingrato!) ${ }^{2}$

La fuerza de este monólogo reside, en buena medida, en el empleo de los verbos, que son uno de los elementos más eficaces de la poesía shakespeareana. Repasémoslos rápidamente en el pasaje y veremos que la mayoría indican acciones vigorosas y violentas: blow, crack, rage, spout, drench'd, drown'd, singe, strike, y los verboides compuestos: Thought-executing, oak-cleaving, all shaking, que con su función adjetiva describen a fires, thunderbolts y thunder, respectivamente.

A tono con esta conmoción, en la misma escena el proscrito Lear recuerda sus funciones reales de juez y hace una majestuosa denuncia de los crímenes en nombre de los dioses:

\section{Let the great gods,}

That keep this dreadful pudder o'er our heads, Find out their enemies now. Tremble thou wretch, That has within thee undivulged crimes, Unwhipp'd of Justice; hide thee, thou bloody hand, Thou perjur'd, and thou simular man of virtue That are incestuous; caitiff, to pieces shake, That under covert and convenient seeming Has practis'd on man's life; close pent-up guilts Rive your concealing continents, and cry These dreadful summoners' grace. I am a man more sinn'd against than sinning.

(Dejad a las deidades poderosas

que hacen estallar este pavoroso tumulto sobre nuestras cabezas

${ }^{2}$ William ShaKespeare, El rey Lear. Trad. de María Enriqueta González Padilla. México, UNAM, 1994 (Col. Nuestros clásicos, 73). 


\begin{abstract}
atrapar ahora a sus enemigos.
Tiembla tú, miserable, que ocultas dentro de ti crímenes ignorados que no alcanzó a castigar la Justicia. Escóndete ya, mano ensangrentada; tú, perjuro, y tú, simulador de virtudes que eres incestuoso. Estremécete infeliz, hasta hacerte pedazos, que bajo capa de honrada apariencia, atentaste contra la vida humana.

Los crímenes reprimidos desgarran vuestros escondidos continentes y demandan la gracia de estos tremendos requeridores. Soy un hombre más ofendido que ofensor. $)^{3}$
\end{abstract}

Qué distintas la coherencia y la solemnidad de estos versos de aquel pasaje en el acto IV, escena vi, en que presa de la locura, el rey discurre en prosa de modo extravagante, sin más apoyo que el hilo conductor de su corriente de conciencia:

LEAR: [...] There's your press money. That fellow handles his bow like a crow-keeper: draw me a clothier's yard. Look, look! a mouse. Peace, peace! this piece of toasted cheese will do't. There's my gauntlet; I'll prove it on a giant. Bring up the brown bills. O! well flown bird; i'th' clout, i'th'clout: hewgh! Give the word.

(LEAR: [...] Ahí está tu paga de enlistamiento. Ese tipo maneja su arco como un espanta-cuervos. Tírame una saeta de las de yarda de pañero. ¡Mira, mira! un ratón. ¡Calma, calma! Ese pedazo de queso asado lo agarra. Ahí está mi manopla; la arrojaré contra un gigante. Traigan las alabardas oscuras. ¡Bravo por tu vuelo, halcón! ¡Diste en el blanco, en el blanco! ¡Ujuu! Dad el santo y seña. $)^{4}$

La idea central de este monólogo es la del candidato a recluta con quien Lear confunde a Edgardo. El rey probablemente pronuncie este parlamento con alguna moneda en la mano que ostente su propia efigie, y que se le ocurre usar como press money para enlistar en el ejército al hijo de Gloucester. El press money era dinero que se entregaba al que se quería obligar a darse de

\footnotetext{
${ }^{3}$ Idem.

4 Ibid., acto IV, escena vi.
} 
alta en el ejército. De ahí se desliza el pensamiento de Lear a la idea de los reclutas que practicaban el tiro de arco, y así surge en su mente el crow-keeper, un chico campesino o el espantajo con el arco bajo el brazo, que se ponía en los sembradios para defenderlos de las aves, lo que le hace pensar al rey en $a$ clothier's yard, una yarda de pañero o vendedor de telas, que era el tamaño normal de la flecha inglesa. El resto del párrafo se explica igualmente por asociaciones mentales, ${ }^{5}$ pero el traductor tiene que conocer una serie de referencias para poder comprender y anotar el pasaje.

Pasando a otra cosa, uno de los aspectos más originales de El rey Lear lo constituyen los incisivos comentarios del bufón (incluidas sus canciones) sobre la situación desventajosa del rey respecto de sus hijas. Como comentarista "amargo", que pone claramente ante el monarca la desgracia de los errores cometidos, los discursos del bufón están llenos de dobles sentidos, de juegos de palabras, de imágenes, de alusiones a fábulas y baladas, de refranes y de sentencias, por ejemplo cuando aconseja:

FOOL: Mark it, Nuncle:

Have more than thou showest, Speak less than thou knowest, Lend less than thou owest, Ride more than thou goest, Learn more than thou trowest, Set less than thou throwest; Leave thy drink and thy whore, And keep in-a-door, And thou shalt have more Than two tens to a score.

(BUfón: Fíjate, tío:

Ten más de lo que aparentas, di menos de lo que sabes, no prestes cuando no tienes, cabalga más que camina, cree menos de lo que oyes, apuesta para que ganes, deja el vino y la putana y estáte metido en casa, y tendrás una veintena en vez de media docena. $)^{6}$

${ }^{3}$ Remito a los lectores a las notas de mi traducción de El rey Lear en la edición citada.

${ }^{6}$ W. ShaKespeare, op. cit., acto I, escena iv. 
O su alusión a lo empobrecido que ha quedado Lear:

He that keeps nor crust nor crumb

Weary of all, shall want some.

That's a sheal'd peascod.

(El que no guarda corteza

ni morona ninguna,

aburrido de todo

necesitará alguna.

Esa es una vaina de chícharo desgranada. $)^{7}$

Huelga decir lo útil que es, al traducir estos pasajes, conservar el metro y la rima hasta donde sea posible; de lo contrario, se estropea la gracia y se pierde el énfasis.

¿Qué diferentes son estos trozos incisivos del bufón de otros de tipo reflexivo en los que un personaje medita acerca de su situación y la generaliza en un lenguaje más adecuado al ensayo que a la urgencia dramática! Así, Edgardo, cuando se queda solo después de que Gloucester y el bufón se han llevado al rey y el espectáculo de la miseria del monarca parece aligerarle a él su propia pesadumbre, dice:

When we our betters see bearing our woes,

We scarcely think our miseries our foes.

Who alone suffers, suffers most i' the mind,

Leaving free things and happy shows behind;

But then the mind much sufferance doth o'erskip,

When grief hath mates, and bearing fellowship.

(Cuando padecer vemos nuestros males

a los que están arriba de nosotros, apenas si acertamos a mirar como enemigas a nuestras desgracias.

Quien sufre solo, sufre con la mente dejando atrás lo ligero y dichoso; mas la mente se ahorra mucha pena si tiene en el sufrir quien la acompañe $y$ alguno que soporte su desgracia.) $)^{8}$

${ }^{7}$ Idem.

8 Ibid., acto III, escena vi. 
Por otra parte, y siguiendo con mi comentario referente a los estilos de la obra, cabe hacer notar que los escasos datos que se tienen de la biografia de Shakespeare parecen dar a entender que en la época de su vida que precedió inmediatamente a su traslado a Londres, y al inicio formal de lo que pudiéramos llamar su carrera dramática en esa capital, tuvo ocasión de rozarse con abogados o de trabajar para ellos, ${ }^{9}$ lo que explica el conocimiento que tiene de la jerga legalista, de la cual más de una vez hace alarde en sus obras. El caso más notable que me viene a la mente es el juicio de Shylock en El mercader de Venecia, en el que Porcia hace brillante ostentación de sopesar y aplicar las minucias de las leyes en contra de la fatal demanda de la libra de carne. En El rey Lear también hay pasajes de corte legalista. Recordemos el preámbulo de la sentencia de Lear a Kent en el acto I, escena i:

Hear me recreant!

On thine allegiance, hear me!

That thou hast sought to make us break our vow, Which we durst never yet, and with strain'd pride

To come betwixt our sentence and our power, Which nor our nature nor our place can bear, Our potency made good, take thy reward.

(¡Escúchame perjuro!

¡Por tu juramento de vasallaje, escúchame! Puesto que has intentado hacernos romper nuestro voto, cosa que nos jamás habríamos hecho, $y$ te atreves con obstinado orgullo a interponerte entre nuestro juicio y nuestro poder, lo cual es intolerable tanto para nuestra naturaleza como para nuestro rango, haremos valer nuestra autoridad: recibe tu castigo.) $)^{10}$

Nótese especialmente la acumulación de cargos y la fuerza legal de la fórmula: Our potency made good, que es el pivote en que gira todo el argumento y la sentencia que vendrá después.

Por su parte, la ensorbecida Goneril, al argüir con su padre en contra del mantenimiento de los cien caballeros, recita también con gran elocuencia un discurso legaloide lleno de retruécanos:

${ }^{9} \mathrm{Cf}$. Anthony BURgess, Shakespeare. Harmondsworth, Penguin Books, 1972.

${ }^{10} \mathrm{~W}$. Shakespeare, op. cit., acto I, escena $i$. 
Sir,

I had thought, by making this well know to you

To have found a safe redress, but now grow fearful,

By what yourself too late have spoke and done,

That you protect this course, and put it on

By your allowance; which, if you should, the fault

Would not 'scape censure, nor the redresses sleep,

Which, in the tender of a wholesome weal,

Might in their working do you that offence,

Which else were shame, that then necessity

Will call discreet proceeding.

(Señor,

pensé que con bien haceros saber esto

encontrariamos un remedio permanente,

mas mucho me temo ahora, por lo que vos mismo

de un tiempo para acá decís y hacéis,

que solapáis este comportamiento

y lo instigáis con vuestra aprobación,

lo cual, de ser asi, sería una falta

que no podría escapar a la censura,

ni dejarse dormir su corrección,

que en interés del bienestar común

podría aplicarse, y daros motivo de agravio,

lo cual, de otra manera, seria una vergüenza,

si no fuera que la necesidad

lo estima como medida prudente.) ${ }^{11}$

En el extremo opuesto de este pasaje prosaico puede citarse la descripción idealizada del llanto de Cordelia que evoca los conceits o imágenes desarrolladas de los sonetos. Esto ocurre en el acto IV, escena iii, en que a la pregunta de Kent sobre si las cartas que le anunciaban la desgracia de su padre y la ingratitud de sus hermanas habian alterado a Cordelia, el caballero contesta con gran rebuscamiento:

Not to rage; patience and sorrow strove

Who should express her goodliest. You have seen

Sunshine and rain at once; her smiles and tears

Were like, a better way; those happy smilets

That play'd on her ripe lip seem'd not to know

1 Ibid., acto 1, escena iv. 
What guests were in her eyes, which parted thence As pearls from diamonds dropp'd, in brief, Sorrow would be a rarity most belov'd If all could so become it.

(Mas no con furia.

El dominio de sí y la aflicción

al par rivalizaban en mostrar su hermosura.

Sin duda habeis visto la luz del sol y la lluvia a un tiempo; pues así eran, aunque de mejor modo, sus sonrisas y sus lágrimas.

Esas discretas sonrisas tan afortunadas que jugaban en sus labios maduros no parecían caer en la cuenta de qué huéspedes estaban en sus ojos, los cuales salian de ahí cual perlas que de diamantes se desprenden. Para abreviar, sería la aflicción una rareza preciadisima si a todas las sentara $\tan$ bien.)

Los similes de este pasaje están tomados de la literatura pastoril del Renacimiento, entonces de moda entre los cortesanos, por ejemplo la Arcadia de Sir Philip Sidney. Nótese cómo la emoción contenida de Cordelia halla expresión en la oposición de contrarios: luz del sol y lluvia, sonrisas y lágrimas, ojos luminosos por el llanto que parecen diamantes que llueven perlas en contraste con las discretas sonrisas felices (smilets) que juegan en los labios maduros.

El traductor debe estar consciente del espesor poético de una obra en la que el lenguaje se forja en el yunque mismo del dramatismo trágico, al grado de que en muchos pasajes los niveles literal y metafórico se funden. ${ }^{12}$ No hay, por ejemplo, nada de decorativo en el lamento de Lear ante Cordelia en la escena vii del acto IV. Las imágenes no describen la experiencia, no la analizan, sino que con gran economía e intensidad se funden con ella:

LEAR: You do me wrong to take me out o'th'grave;

Thou art a soul in bliss; but I am bound

${ }^{12}$ Cf. Inga-Stina EwBANK, "Shakespeare's Poetry", en Kenneth MUIR y S. SCHOENBaUm, eds., A New Companion to Shakespeare Studies. Cambridge, Cambridge University Press, 1979. 
Upon a wheel of fire, that mine own tears

Scald like lead.

(LEAR: Hacéis mal en sacarme del sepulcro.

Tú eres un alma bienaventurada, pero yo estoy atado a una rueda de fuego, que mis propias lágrimas escaldan como plomo derretido.)

Dada su importancia, Cordelia habla relativamente poco en la obra. Desde el principio, su respuesta a la demanda de Lear de que le manifieste cuánto lo quiere carece de ese arte glib and oily, fluido y untuoso, que es el biombo detrás del cual las hermanas mayores esconden su hipocresía. ¡Cuán directo y sencillo suena todo lo que ella dice tras los large speeches, los discursos ampulosos de ellas!

CORDELIA: Good my lord,

You have begot me, bred me, lov'd me: I

Return those duties back as are right fit,

Obey you, love you, and most honour you...

(CoRDElia: Bondadoso señor,

no sólo el ser me disteis, sino que me habéis querido

y alimentado. Yo os vuelvo mi gratitud

cual se debe: os obedezco, amo y venero... $)^{13}$

Es un estilo sin hipérboles, sin imágenes, sin adornos de ninguna especie, la mejor prueba de que el autor, llegado en esta obra al pleno dominio de su arte, usaba la lengua con gran discriminación. Había aprendido a servir el propósito dramático por encima de cualquier otra solicitación, y no vacilaba, cuando aquél lo requería, en dar jaque mate a la verborrea.

También es pertinente mencionar, en lo que se refiere al estilo, el uso de you y de thou en El rey Lear, lo cual reviste una gran cantidad de matices sutiles y complejos.

En efecto, se dice a menudo que en 1600 you era la fórmula de cortesía, y thou era coloquial o insultante. Esto es cierto en muchos casos, por ejemplo en la reprimenda de Lear a Kent en el acto I, escena $i$, que cité más arriba:

LEAR: Hear me recreant!

On thine allegiance, hear me!

${ }^{13}$ W. ShakeSpeare, op. cit., acto 1 , escena i. 
(Lear: ¡Escúchame perjuro!

¡Por tu juramento de vasallaje, escúchame!)

Y en la respuesta de Kent a Lear:

KENT: Fare thee well, King; sith thus thou wilt appear, Freedom lives hence, and banishment is here.

(KENT: Adiós, oh rey; pues que quieres mostrarte así, fuera reina la libertad y el destierro está aquí.)

Pero el tuteo prevalece en las palabras de Kent a Cordelia:

KENT: The Gods to their dear shelter take thee maid That justly think 'st and hast most rightly said!

(KENT: Los dioses te protejan, oh doncella, porque el buen juicio tus palabras sella.) ${ }^{14}$

$Y$ es que thou y sus derivados y concordancias verbales también tienen el sentido de afecto o confianza. Con todo, es dificil establecer reglas generales a este respecto, porque hay muchisimos casos en que you y thou operan de acuerdo con el concepto lingüístico de contraste activo que sirve para oponer lo excepcional o sobresaliente a lo usual. Así, por ejemplo, Lear tutea habitualmente a sus hijas, sin embargo, su manera de mostrar su resentimiento con Goneril por la fría acogida de que ha sido objeto en su casa, es emplear you en vez del thou afectuoso que había usado en la primera escena del acto I:

LEAR: Are you our daughter?

(LEAR: ¿Sois vos nuestra hija?) ${ }^{15}$

LEAR: Your name, fair gentlewoman?

(LEAR: ¿Vuestro nombre, bella señora?) ${ }^{16}$

\footnotetext{
${ }^{14}$ Idem.

${ }^{15}$ Ibid., acto I, escena iv.

${ }^{16}$ Idem.
} 
En cambio en el acto II, escena iv, vuelve al tuteo, al refugiarse tiernamente en Regan por las ofensas de Goneril:

LEAR: Beloved Regan,

Thy sister's naught. O Regan! she had tied

Sharp-tooth'd unkindness, like a vulture, here.

(Points to his heart.)

I can scarce speak to thee; thou'lt not believe

With how deprav'd quality. O Regan!

(LEAR: ¡Amada Regan, tu hermana es infame!

¡Ay Regan, ha encajado

la crueldad de agudo diente como buitre aquí!

(Apunta a su corazón)

Apenas puedo hablarte.

No puedes creer con qué perversidad... ¡Oh Regan!)

Al estudiar los estilos de un autor tan pródigo como Shakespeare, observa G. L. Brook, ${ }^{17}$ es necesario tener en cuenta qué variedades de la lengua se usaban corrientemente en su época. Entre ellos figuran, según este autor: a) el buen inglés, que es el que domina en sus obras, y que era el que prevalecía en la corte del rey y en las ciudades y villas respetables, y que es el único que aceptan los buenos lingüistas y que califican de "natural, puro y más aceptable en el país"; b) el lenguaje de las regiones fronterizas muy apartadas de la capital o muy visitadas por extranjeros; c) el lenguaje que usaban los letrados que pecaban muchas veces de afectación y culteranismo, y d) el que usa la gente sin educación y los rústicos. De este último hallamos en El rey Lear un ejemplo notable en labios de Edgardo (acto IV, escena vi):

Good gentleman, go your gait, and let poor volk pass. And 'chud ha' bin zwagger'd out of my life, 't would not ha 'bin zo long as 'tis by a vortnight. Nay, come not near th'old man; keep out, che vor'ye or ise try whither your costard or my ballow be the harder. Chill be plain with you.

Se trata, comenta Kenneth Muir, ${ }^{18}$ de un dialecto convencional que se usa-

${ }^{17}$ G. L. BrooK en su introducción a The Language of Shakespeare. Londres, André Deutsch, 1976.

${ }^{18}$ Notas a The Arden Shakespeare King Lear. Londres, Methuen, 1985, p. 173. 
ba en el teatro y que "se aproximaba al de Somersetshire", aunque también se utilizaba para otros condados. $Y$ añade que es idéntico al dialecto de Devonshire que se usa en The London Prodigal (1605), puesta en escena por la compañía de Shakespeare.

Mi traducción de este pasaje reza así:

Buen caballero, andi asté su camino y deje su mercé vivir a los probes. Si pa' que perdiera yo la vida sirvieran las bravatas, ya estuviera yo tendido haci dos semanas. No si arrime asté al anciano; apártisi bien; si no, veremos si es más dura su mollera de asté que esti garrote mío. Se lo digo de plano a asté.

Lo cual corresponde al habla regional de algunas personas, conocidas como gente de campo en nuestro país. Nótese cómo, so capa de cortesía, "buen caballero", "su mercé", Edgardo advierte con gran contundencia al intruso que deje tranquilo a Gloucester, so pena de perder la vida. Nótese también en el original inglés el empleo de costard, literalmente un tipo de manzana usado humoristicamente para significar la cabeza, y el de ballow, que es un regionalismo para significar cudgel, garrote.

La parodia, observa Brook, se usa frecuentemente en Shakespeare con propósitos de crítica o burla. En el acto II, escena ii, de nuestra obra, cuando Kent es amonestado severamente por su rudeza de trato con Osvaldo, replica dirigiéndose a Cornwall con la parodia de los formulismos que usaría un cortesano adulador:

KENT: Sir, in good faith, in sincere verity, Under th'allowance of your great aspect, Whose influence like the wreath of radiant fire On flicking Phoebus front...

CORNWALL: What mean'st by this

KENT: To go out of my dialect which you discommend so much.

(KENT: Señor, de buena fe, con toda sincera verdad, con la aprobación de aqueste vuestro imponente aspecto, cuya influencia, cual guirnalda de radiante fuego flameante sobre la frente de Febo... CORNWALL: ¿Qué intentas con esto?

KENT: Salirme de mi estilo que vos criticáis tanto.) 
Para concluir, quiero citar algo que dice Ifor Evans y que me parece pertinente, en el sentido de que, como dramaturgo, Shakespeare "estaba siempre en una especie de peligro espléndido, porque la lengua lo deleitaba tanto, que tenía gusto en las palabras por si mismas, y era como si ellas conocieran su debilidad y estuvieran siempre dispuestas a dominarlo. Corría el riesgo, pues, de quedar abrumado por la exuberancia de su propio genio verbal. En algunas obras podia dar salida libremente a todas sus energías linguiisticas como lo hizo en Trabajos de amor perdido. A veces era analítico y tendía à criticarse a sí mismo en el uso de la lengua, y los resultados de ello pueden apreciarse en Romeo y Julieta y en Hamlet... Pero a veces parece haber unidad entre los elementos críticos y los creativos, y esto conduce al triunfo lingüístico de $E l$ rey Lear". ${ }^{19}$

${ }^{19}$ 1. EvaNs, “Introducción”, en op. cit., pp. ix-x. 